\title{
Síndrome de Schnitzler: Entidade Clínica a ser Considerada em Doentes com Urticária Crónica
}

\section{Schnitzler Syndrome: A Clinical Entity to be Considered in Patients with Chronic Urticaria}

Ana Catarina Carvoeiro ${ }^{1}$, Sérgio Silva², António Sampaio², Alberto Leite², Mariana Couto ${ }^{2}$, Paulo Bettencourt ${ }^{1,2}$

\section{RESUMO}

INTRODUÇÃO: A divulgação de condições clínicas raras, em que a intervenção médica modifica significativamente a abordagem dos doentes, é importante, pois, além de alertar para a sua existência, permite a partilha de conhecimento com potencial impacto na prática clínica.

CASO CLÍNICO: Doente do sexo masculino, com 32 anos de idade, previamente avaliado em Dermatologia e Imunoalergologia por urticária crónica. Refere aparecimento de rash urticariforme crónico acompanhado de astenia e artralgias, com oito anos de evolução. Medicado com anti-histamínicos e ciclosporina sem resolução da sintomatologia. Foi referenciado a Medicina Interna por aumento persistente e crescente da velocidade de sedimentação (65 mm). No estudo dirigido efetuado, identificou-se uma gamapatia monoclonal IgM de cadeias kappa. Diagnosticou-se o doente, como tendo síndrome de Schnitzler. Iniciou terapêutica com colquicina com resolução completa dos sintomas. DISCUSSÃO: A síndrome de Schnitzler é uma entidade rara, cuja patofisiologia não se encontra completamente compreendida, sabendo-se que apresenta um perfil autoinflamatório. O diagnóstico da síndrome de Schnitzler exige elevada suspeição clínica, pelo que a descrição de casos como o apresentado é crucial, para que esta seja uma entidade conhecida e discutida, com uma maior notoriedade.

PALAVRAS-CHAVE: Síndrome de Schnitzler; Urticária 


\section{ABSTRACT}

INTRODUCTION: The charring of rare clinical conditions where the clinicians can significantly change patients' management is relevant, it alerts to its recognition and permit to share knowledge with potential clinical impact.

CASE REPORT: We present a 32-year-old male that has been previously evaluated in Dermatology and Immunoalergology appointments due to chronic urticaria. He had urticarial rash for eight years. He complained of asthenia and arthralgia. He has been on anti-histaminics and posteriorly cyclosporine has been added without complete resolution of symptoms. He has been referred to Internal Medicine appointment due to elevated sedimentation velocity rate $(65 \mathrm{~mm})$. In the diagnostic study, an IgM/K monoclonal gammopathy was identified. Schnitzler syndrome was diagnosed and the patient began with colchicine with total resolution of symptoms.

DISCUSSION: Schnitzler syndrome is a rare condition with a still not completely understood physiopathology. It has been known as an auto-inflammatory condition. Schnitzler syndrome diagnosis requires high suspicion, so descriptions as ours are important to give notoriety to this condition.

KEYWORDS: Schnitzler Syndrome; Urticaria

\section{INTRODUÇÃO}

A síndrome de Schnitzler (SS) foi descrita pela primeira vez em 1972 por Liliane Schnitzler, ${ }^{1}$ tendo sido, desde então, descritos aproximadamente 300 casos. $^{2}$

A SS é mais comum nos homens com um rácio homem/ mulher de 1,76 e a idade média de aparecimento de sintomas é de 51,6 anos. ${ }^{3}$ A SS é uma patologia rara, adquirida, autoinflamatória que se caracteriza, fundamentalmente, por uma urticária crónica e por uma gamapatia monoclonal associadas a febre recorrente, dores articulares, musculares ou ósseas, hepatoesplenomegalia, linfadenopatias e pela elevação de marcadores de fase aguda. ${ }^{4}$

Não existe nenhum exame biológico ou outro qualquer procedimento que possibilite, de forma inequívoca, o diagnóstico definitivo de SS. A média de tempo para se determinar o diagnóstico é de aproximadamente cinco anos. ${ }^{3}$ Em 2001, Lipsker et al sugeriu os primeiros critérios de diagnóstico, tendo como referência uma revisão de 52 casos da literatura e a sua experiência médica com quatro doentes. ${ }^{5}$ Em 2012, numa conferência de especialistas, foram definidos novos critérios de diagnóstico, conhecidos como critérios de Strasbourg, ${ }^{2}$ a partir dos quais se introduziu a distinção entre os doentes que apresentam uma SS definitiva ou provável. ${ }^{3}$ A SS tem uma evolução para a cronicidade, estando, habitualmente, associada a elevada morbilidade. O prognóstico está, fundamentalmente, dependente na progressão para doenças linfoproliferativas, o que se estima que ocorra em 15\% - 20\% dos doentes. ${ }^{4}$ Atualmente, estudos recentes têm demonstrado uma boa resposta terapêutica ao tratamento com Anakinra. ${ }^{4,6}$ Tendo em atenção a sua raridade e a ausência de testes de diagnóstico específicos, a SS encontra-se, ainda, nos dias de hoje, sub- diagnosticada. O caso clínico descrito pretende realçar a importância da identificação de sinais/sintomas e de alterações analíticas que alertem para a presença de uma possível SS, uma vez que o seu diagnóstico precoce poderá ter impacto significativo e favorável na qualidade de vida dos doentes.

\section{CASO CLÍNICO}

Apresentamos um doente de 32 anos, sem antecedentes de relevo à história médica pregressa e familiar. Desde 2008, com lesões cutâneas maculares eritematosas não pruriginosas com atingimento dos membros e do tronco (Fig. 1). O rash urticariforme apresentou-se, inicialmente, em surtos uma vez por semana, os quais duravam aproximadamente três dias. Cada mácula tinha uma duração inferior a 24 horas, com resolução espontânea, sem lesão residual associada. Refere astenia intensa, artralgias e episódios raros de hipertermia e sudorese noturna. Sem queixas álgicas musculares, ósseas ou outros sintomas, nomeadamente angioedema. Não foram identificados fatores desencadeantes ou de alívio para a sintomatologia. Orientado em consulta externa de Dermatologia e Imunoalergologia desde 2014, medicado com anti-histamínicos e ciclosporina. Em novembro de 2016, foi referenciado à consulta de Medicina Interna no Hospital CUF Porto por elevação persistente da velocidade de sedimentação (VS). No momento da consulta, refere apresentar cerca de 1 a 2 episódios de urticária por semana. Ao exame físico, não se observavam máculas urticariformes ou qualquer lesão cutânea, não apresentando adenopatias ou hepatoesplenomegalia. Do estudo analítico realizado, de salientar: os valores sustentadamente elevados do parâmetro, VS que, em novembro de 2016, era de 65 mm e o valor da imunoglobulina M, cujo valor mais recente correspondia a 680 mg/dL. Após rea- 

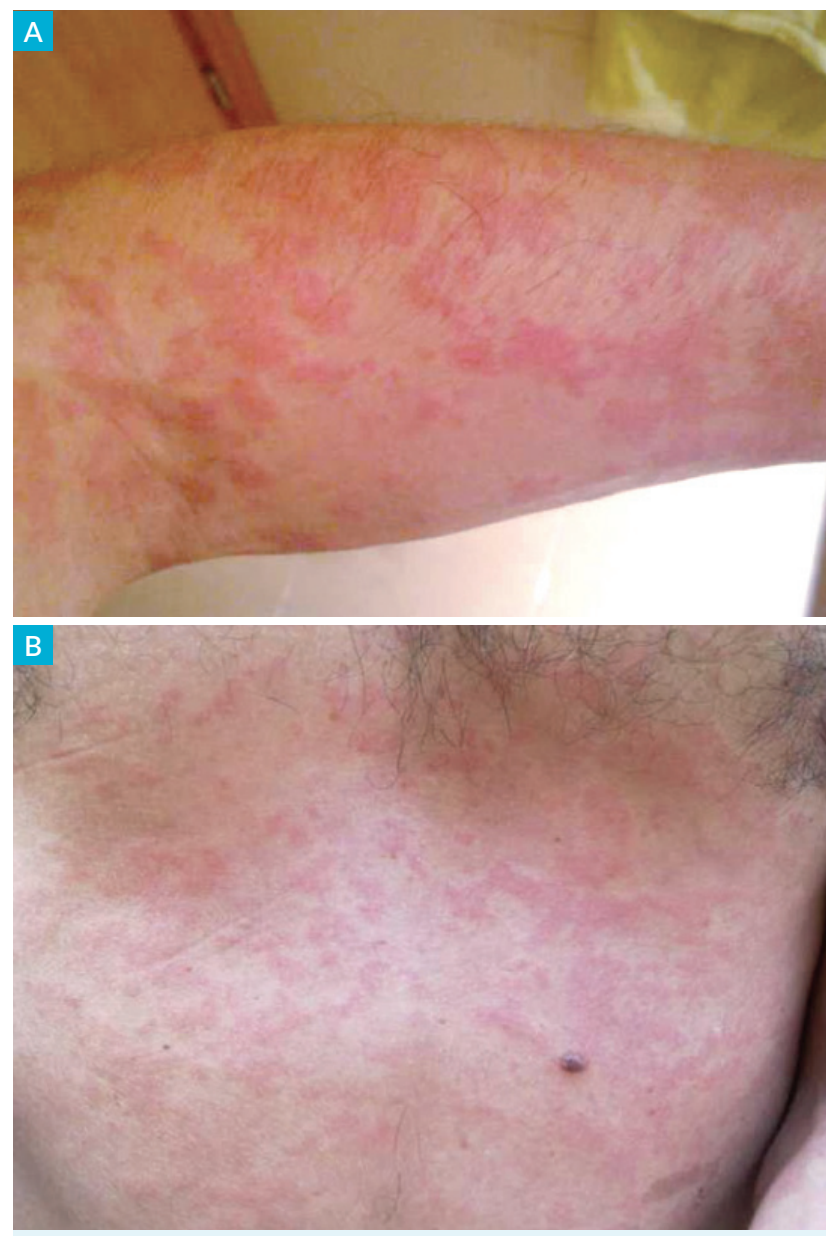

FIGURA 1. Máculas eritematosas: A- Máculas eritematosas - membro superior esquerdo; B- Máculas eritematosas - região superior do tronco.

lização de imunoeletroforese de proteínas, verificou-se um pico monoclonal de lgM/kappa. Realizou aspirado de medula óssea, que afastou proliferação linfoplasmocitária (macroglobulinemia da Waldestrom). Foi realizado o diagnóstico de síndrome de Schnitzler, sendo o doente medicado com colquicina. Decorridos três meses, o doente apresentava-se totalmente assintomático. Os valores de VS desceram para $37 \mathrm{~mm}$. Foi suspensa terapêutica com ciclosporina, mantendo-se assintomático com colquicina na dose de $1 \mathrm{mg}$ od.

\section{DISCUSSÃO}

A SS é uma entidade extremamente rara, cuja patofisiologia não se encontra completamente compreendida. ${ }^{4}$ A SS apresenta características autoinflamatórias, verificando-se uma proliferação clonal de plasmócitos produtores de IgM, acompanhada por níveis elevados de IL-6 e de outras citocinas inflamatórias. Relativamente aos mecanismos patofisiológicos, importa, ainda, realçar a resposta significativa dos doentes ao antagonista do recetor da IL-1 (anakinra), o que sugere um efeito patogénico direto desta interleucina. ${ }^{4}$
O conhecimento da SS em Portugal é ilustrado numa série de nove casos, divulgada pelos colegas do Centro Hospitalar de Coimbra.?

De acordo com os critérios de Strasbourg, ${ }^{3}$ um diagnóstico considera-se definitivo se o doente apresentar dois critérios obrigatórios - rash urticariforme recorrente e uma gamapatia monoclonal IgM (em aproximadamente 88\% dos casos $^{2}$ ) ou lgG - assim como dois dos critérios minor - febre recorrente $\left(>38^{\circ} \mathrm{C}\right)$, sinais objetivos de remodelação óssea com ou sem dor associada, elevação da proteína C-reativa ou leucocitose e infiltrado neutrofílico na derme aquando da biópsia da pele. Um diagnóstico considera-se provável se apenas estiverem presentes, para além dos critérios obrigatórios, um critério minor, pelo menos. Atendendo ao descrito anteriormente, o doente cumpria os critérios major de diagnóstico, apresentando também elevação crescente da VS. $O$ doente apresentava artralgias e episódios de hipertermia sem objetivação de febre. Não foi realizada biópsia das lesões, pelo que se desconhecem as características histopatológicas.

Importa realçar que o exame musculoesquelético é crucial na SS, uma vez que a dor óssea constitui um dos principais sintomas e causas de morbilidade. ${ }^{8}$ Apesar de nenhum dos achados imagiológicos ser específico da SS, o estudo radiográfico mostra recorrentemente lesões escleróticas. A cintigrafia óssea é considerada o exame de eleição para documentar o envolvimento ósseo da SS.?

Ainda, no que concerne às manifestações clínicas da SS, de mencionar o recente caso clínico de uma doente diagnosticada com SS há 22 anos, o qual reporta o desenvolvimento de aortite na sequência da evolução da doença, cuja remissão foi atingida após 10 meses de tratamento com anacinra. ${ }^{10}$ A provável associação entre a SS e o surgimento de aortite, realça a importância da realização de uma tomografia por emissão de positrões com fluordesoxiglicose (PET ${ }^{18} \mathrm{~F}$ - FDG), ${ }^{10}$ sempre que se verifiquem sintomas atípicos, como epigastralgias, perda ponderal, astenia e anorexia marcadas e após a exclusão de outras hipóteses de diagnóstico.

De acordo com os sinais e sintomas que caracterizam a SS, deve ser, primariamente, estabelecido o diagnóstico diferencial com a doença de Still de início tardio, a síndrome periódica associada à criopirina (CAPS), especialmente a síndrome de Muckle-Wells, o lúpus eritematoso sistémico, a urticária crónica idiopática e as vasculites urticariforme e crioglobulinémica. ${ }^{11}$

O tratamento da SS pode ser difícil, insatisfatório, sendo a remissão atingida raramente, não existindo ainda uma abordagem terapêutica consensual. ${ }^{12}$ 
Em doentes sem atingimento significativo na sua qualidade de vida, a colquicina, a pefloxacina, os anti-inflamatórios não esteroides (AINES) e a hidroxicloroquina podem ser opções de tratamento em que se verificou uma boa relação risco/benefício. ${ }^{3}$ Por outro lado, em doentes muito sintomáticos ou que apresentem os parâmetros inflamatórios constantemente alterados e superiores ao normal, deve ponderar-se tratamento com anacinra, que geralmente induz remissão completa. ${ }^{3}$ Em 2005, foi descrito o primeiro caso em que se obteve uma resposta favorável à terapêutica com anacinra, tendo sido, subsequentemente, confirmada a sua eficácia num estudo de coorte multicêntrico e retrospetivo. ${ }^{13} \bigcirc$ canacinumab, outro anticorpo monoclonal humanizado específico anti- IL1, também tem sido identificado como uma possível opção de tratamento. ${ }^{14}$ Nos doentes submetidos a tratamento com antagonistas da IL-1, a remissão ocorrerá em, aproximadamente, $83 \%$ de todos os casos. ${ }^{13}$ No subgrupo específico de doentes que não respondem favoravelmente à anacinra, pode ser ensaiada terapêutica com tocilizumab (anti-IL6), que tem demonstrado boa eficácia. $^{7}$

A taxa de mortalidade não se encontra aumentada em doentes com SS, sendo que a sobrevida após 15 anos do diagnóstico é sobreponível à da população em geral (94\%). ${ }^{15}$ O prognóstico está dependente da progressão para doenças linfoproliferativas, incluindo macroglobulinemia de Waldenstrom, mieloma múltiplo, linfoma de células B marginal. De facto, a terapêutica com antagonistas da IL-1, apesar da sua eficácia na remissão de sintomas, não parece ter impacto no componente monoclonal, sendo que, provavelmente, também não previne a ocorrência das mencionadas doenças linfoproliferativas. ${ }^{7}$ No curso evolutivo da SS, há também um risco aumentado de progressão para amiloidose AA que deverá ser considerado. ${ }^{\circledR}$ No caso que se descreve, após realização de mielograma, não se verificou qualquer proliferação plasmocitária.

\section{CONCLUSÃO}

Em conclusão, o diagnóstico de SS exige um alto grau de suspeição clínica, pelo que a descrição de casos como o apresentado é crucial, para que esta seja uma entidade amplamente discutida e conhecida. $\bigcirc$ diagnóstico precoce da SS é bastante importante, uma vez que atualmente se dispõe de armas terapêuticas (anacinra) eficazes, que possibilitam um incremento significativo na qualidade de vida destes doentes. Após o diagnóstico de SS, é relevante que haja um seguimento clínico dirigido, atendendo à possível progressão para doenças linfoproliferativas, inerente a esta patologia.
CONFLITOS DE INTERESSE: Os autores declaram não ter qualquer conflito de interesse na realização do presente trabalho.

FONTES DE FINANCIAMENTO: Não houve qualquer fonte de financiamento na realização do presente trabalho.

CONFIDENCIALIDADE DOS DADOS: Os autores declaram ter seguido os protocolos da sua instituição acerca da publicação dos dados de doentes.

PROTEÇÃO DE PESSOAS E ANIMAIS: Os autores declaram que os procedimentos seguidos na elaboração do presente trabalho estão em conformidade com as normas das comissões de investigação clínica e de ética, bem como da declaração de Helsínquia e da Associação Médica Mundial.

CONFLICTS OF INTEREST: The authors declare that they have no conflicts of interest.

FINANCIAL SUPPORT: This work has not received any contribution, grant or scholarship.

CONFIDENTIALITY OF DATA: The authors declare that they have followed the protocols of their work center on the publication of data from patients.

PROTECTION OF HUMAN AND ANIMAL SUBJECTS: The authors declare that the procedures followed were in accordance with the regulations of the relevant clinical research ethics committee and with those of the Code of Ethics of the World Medical Association (Declaration of Helsinki).

\section{REFERÊNCIAS}

1. Schnitzler L. Lésions urticariennes chroniques permanentes (érythème pétaloide?) Cas cliniques. Journée Dermatol d’Angers. 1972;46.

2. Gusdorf L, Asli B, Barbarot S, Neel A, Masseau A, Puechal X, et al. Schnitzler syndrome: validation and applicability of diagnostic criteria in real-life patients. Allergy. 2017;72:177-82.

3. Simon A, Asli B, Braun-Falco M, De Koning H, Fermand JP, Grattan C, et al. Schnitzler's syndrome: diagnosis, treatment, and follow-up. Allergy. 2013;68:562-8.

4. Lipsker D. The Schnitzler syndrome. Orphanet J Rare Dis 2010;5:38.

5. Lipsker D, Veran Y, Grunenberger F, Cribier B, Heid E, Grosshans E. The Schnitzler syndrome. Four new cases and review of the literature. Medicine 2001;80:37-44.

6. Gouveia Al, Micaelo M, Pierdomenico F, Freitas JP. Schnitzler syndrome: a dramatic response to anakinra. Dermatol Ther. 2016:6:299-302.

7. Gameiro A, Gouveia M, Pereira M, Tellechea O, Goncalo M. Clinical characterization and long-term follow-up of Schnitzler syndrome. Clin Exp Dermatol. 2016;41:461-7.

8. Gusdorf L, Lipsker D. Schnitzler syndrome: a review. Curr Rheumatol Rep. 2017;19:46. 
9. Niederhauser BD, Dingli D, Kyle RA, Ringler MD. Imaging findings in 22 cases of Schnitzler syndrome: characteristic para-articular osteosclerosis, and the "hot knees" sign differential diagnosis. Skeletal Radiol. 2014;43:905-15.

10. Bursztejn AC, Imperiale A, Lipsker D. Aortitis: A new feature of Schnitzler syndrome. JAAD Case Rep. 2017;3:454-6.

11. Ruiz-Villaverde R, Bueno-Rodriguez A, Sanchez-Cano D. Beyond Urticaria: Schnitzler Syndrome. Balkan Med J. 2017;34:478-9.

12. Cravo GM, Vieira R. Síndrome de Schnitzler - desrição de 7 casos clínicos. Rev Soc Port Dermatol Venereol. 2008;66:42334.

13. Neel A, Henry B, Barbarot S, Masseau A, Perrin F, Bernier C, et al. Long-term effectiveness and safety of interleukin-1 receptor antagonist (anakinra) in Schnitzler's syndrome: a French multicenter study. Autoimmun Rev. 2014;13:1035-41.

14. de Koning HD, Schalkwijk J, van der Ven-Jongekrijg J, Stoffels M, van der Meer JW, Simon A. Sustained efficacy of the monoclonal anti-interleukin-1 beta antibody canakinumab in a 9-month trial in Schnitzler's syndrome. Ann Rheum Dis. 2013;72:1634-8.

15. Tinoco G, Kanji R, Moola D. Schnitzler's syndrome: a case report. Case Rep Med 2013;2013:956464. 